\title{
The effects of musical fit on choice between two competing foods.
}

\begin{abstract}
Two experiments investigated the impact of musical "fit" on consumer choice. In Experiment 1, Malaysian participants of Malay, Indian, or Chinese ethnicity chose between Malay and Western food while either Malay or Western music played in the background. Participants tended to choose Malay food, irrespective of the type of music played. Experiment 2 repeated the same basic methodology but presented a more ambiguous choice scenario of Malay versus Indian food while either Malay or Indian music played in the background. Food choices corresponded with the ethnicity of the background music. This suggests that musical "fit" can influence product choice, consistent with previous research, but only when consumers do not have a clear existing preference for one product over another.
\end{abstract}

Keyword: Music; Consumers; Food; Preference; Choice. 